ISSN 1991- 8690

website : http:// jsci.utq.edu.iq

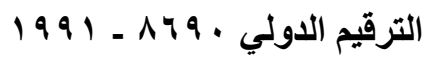

Email: utjsci@utq.edu.iq

\title{
Efficient High GainYtterbium Doped Lead Fluoroborate Glasses Fiber Amplifiers
}

\author{
AbdulKareem H. Dagher \\ Jabir Hussien Al- asadi \\ Muayad Jabbar Kareem
}

\section{$\underline{\text { Abstract }}$}

This paper is based on the numerical solution of the rate equations model and their gain dependences are discussed. Simulation of the amplifier gain versus the pump power, amplifier length, ion concentration and core radius has been done. In order to keep the fiber amplifiers doped with ytterbium as short as possible with high gain, it is best to increase the doped concentration. For $10 \mathrm{~m}$ amplifier length, pump power of $25 \mathrm{~mW}$, core radius of $2.5 \mu \mathrm{m}$ and $3.5 \times 10^{25} \mathrm{ion} / \mathrm{m}^{3}$ doping concentration, the gain is $60 \mathrm{~dB}$. Increasing of the core radius would increase the threshold pump power and at the above same conditions, the optimum gain is at $5 \mu \mathrm{m}$ core radius.

Keywords: Ytterbium Doped Fiber Amplifier (YDFA), Single mode، Population inversion and Three-level rate equations.

$$
\begin{aligned}
& \text { مضخم ليف زجاج فلورويورات الرصاص الكفوء عالي الريح المطعم بالاترييوم }
\end{aligned}
$$

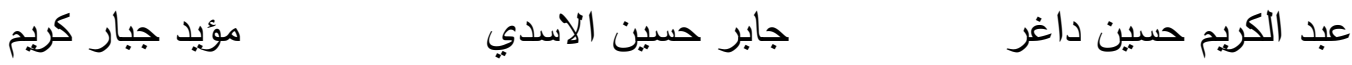

\section{Introduction}

Fiber lasers and amplifiers have attracted great interest recently, because they offer the advantages of compact size, high gain, guided mode propagation and better stability [1]. Ytterbium doped fiber amplifier YDFA has a great potential because it does not have some of the drawbacks associated with erbium-doped amplifier: excited state absorption phenomenon that can reduce the pump efficiency and concentration quenching by intrinsic energy transfer do not occur, and high doping levels are possible [2]. Thus, it offers high output power (or gain) with a smaller fiber length moreover, excellent power conversion efficiency. YDFA's have a simple energy level structure and provide amplification over a broad wavelength range from 975 to $1200 \mathrm{~nm}$. YDFA's have great potential in many applications, including power amplification, sensing applications, free-space laser communications, and chirped-pulse amplification of ultra-short pulses [3].

\section{Rate Equations Model}

Ytterbium is a two level system having four Stark levels in the lower manifold $2 F 7 / 2$ and three Stark levels in upper manifold $2 \mathrm{~F} 5 / 2$, as shown in figure(1). Rate equations model which describe the gain and propagation characteristics of the Yb-doped fiber amplifier operating at $968 \mathrm{~nm}$ has been done. N1 and $\mathrm{N} 2$ are introduced as fractional densities of ions in the energy levels $2 F 7 / 2$ and $2 F 5 / 2$ respectively. In the initial condition there is no pump, $\mathrm{N} 2=0$ and $\mathrm{Nt}=\mathrm{N} 1$. 


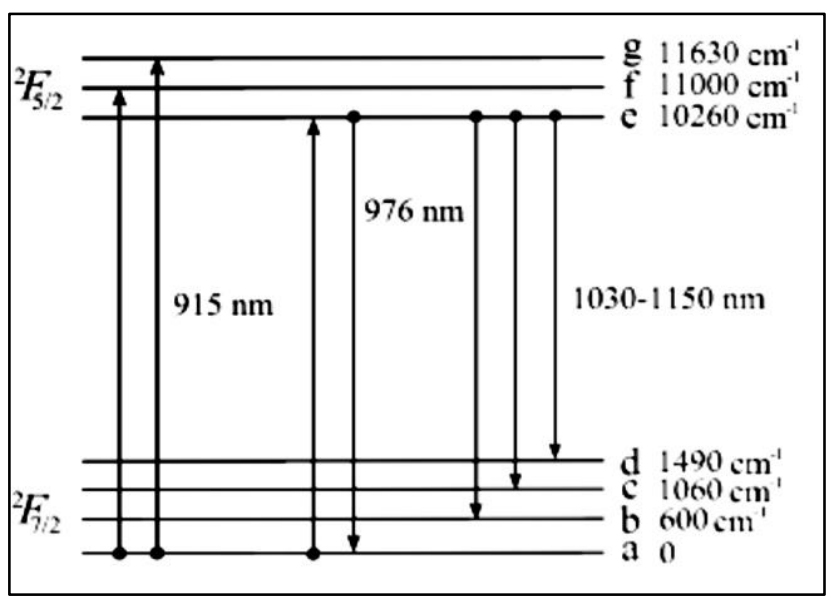

Figure(1): energy level diagram illustrating the ytterbium ground ${ }^{2} F_{7 / 2}$ and excited ${ }^{2} F_{5 / 2}$ state manifolds and possible transitions between the sub-levels [4].

The following equations show the atomic transition for these ion populations $[5,6]$ :

$$
\begin{aligned}
& \frac{d N_{1}}{d t}=-W_{S a} N_{1}+W_{S e} N_{2}+A_{21} N_{2}-W_{P} N_{1} \\
& \frac{d N_{2}}{d t}=W_{S a} N_{1}-W_{S e} N_{2}-A_{21} N_{2}+W_{P} N_{1}
\end{aligned}
$$

where WP is the pump transition, Wsa, Wse is the signal transition for absorption and emission respectively and A21 is the spontaneous emission coefficient, the above factors can obtain by the following relations [4].

$$
\begin{aligned}
& W_{P}\left(v_{P}\right)=\sigma_{P a} \frac{I_{P}}{h v_{P}} \\
& W_{S e}\left(v_{s}\right)=\sigma_{e} \frac{I_{s}}{h v_{s}} \\
& W_{S a}\left(v_{s}\right)=\sigma_{a} \frac{I_{s}}{h v_{s}}
\end{aligned}
$$

IP, S represents the intensity of the pump and signal radiation.

$$
\begin{aligned}
& I_{i}=\frac{P_{i}}{A} \quad, \mathrm{i}=\mathrm{P}, \mathrm{s} \\
& A_{21}=\frac{1}{\tau_{21}}
\end{aligned}
$$

where $\sigma \mathrm{a}$ and $\sigma \mathrm{e}$ are the signal absorption and emission cross-sections, $\sigma \mathrm{Pa}$ is pump absorption cross section, $\nu \mathrm{P}$ and $v \mathrm{~S}$ are the pump and signal frequencies, respectively, $\tau 21$ is the fluorescent lifetime of the excited state, $\mathrm{Pi}$ is the pump and signal power and $\mathrm{A}$ is the cross section area of fiber [7]. At steady state ( $\frac{d N_{i}}{d t}=\mathrm{O}$ ), with some arrangements yields,

$$
N_{1}=\frac{W_{S e}+A_{21}}{W_{S a}+W_{P}} N_{2}
$$

In order to obtain gain, the stimulated emission from state 2 to state 1 must be greater than the absorption from state 1 to state 2 . This condition implies that the population in state 2 must be maintained at a greater level than that of state 1 i.e. population inversion, more than half the ground state atoms must be pumped into the meta stable state to achieve population inversion. The degree of population inversion is expressed by population inversion factor nSP and defined as [8]:

$$
n_{s p} \equiv \frac{N_{2}}{N_{2}-N_{1} \frac{\sigma_{P a}}{\sigma_{P \varepsilon}}}
$$

where $(\sigma \mathrm{Pa} / \sigma \mathrm{Pe})$ close to 1 for $\mathrm{Yb}+3$. Substitute Eq.(8) and (7) into (9) yield

$n_{s p} \equiv \frac{N_{2}}{N_{2}-N_{1}}=\frac{W_{P} \tau_{21}+W_{S e} \tau_{21}}{W_{P} \tau_{21}+\left(W_{S q}-W_{S \varepsilon}\right) \tau_{21}-1}$

Therefore, nsp is related to the pump and signal powers by WP and Ws respectively. The total ion density $(\mathrm{Nt})$ is equal to [6]

$$
N_{t}=N_{1}+N_{2}
$$

The relative population inversion $(\Delta \mathrm{N} / \mathrm{N})$ defined as [9]

$$
\frac{\Delta N}{N_{t}}=\frac{N_{2}-N_{1}}{N_{t}}
$$

From Eqs.(8) and (11) we have

$$
\begin{aligned}
& N_{1}=\frac{W_{S e} \tau_{21}+1}{W_{P} \tau_{21}+\left(W_{S a}+W_{S e}\right) \tau_{21}+1} N_{t} \\
& N_{2}=\frac{W_{S a} \tau_{21}+W_{P} \tau_{21}}{W_{P} \tau_{21}+\left(W_{S a}+W_{S e}\right) \tau_{21}+1} N_{t}
\end{aligned}
$$

Subtract Eq. (13) from (14) with the aid of (12) we get: 
$\frac{\Delta N}{N_{t}}=\frac{N_{2}-N_{1}}{N_{t}}=\frac{W_{P} \tau_{21}+\left(W_{S a}-W_{S e}\right) \tau_{21}-1}{W_{P} \tau_{21}+\left(W_{S a}+W_{S e}\right) \tau_{21}+1}$

When the pumping rate is high enough, or WP $>$ Ws and WP $>>1 / \tau 21, N_{2}-N_{1} \approx N_{t}$. In this case, the medium gain is approximately [10]:

$g_{o}=\left(\sigma_{\varepsilon} N_{2}-\sigma_{a} N_{1}\right) \approx \sigma_{\varepsilon} N_{t}=g^{*}$

where $g *$ is the upper limit of the medium gain constant. The ratio emission-to-absorption cross sections of the signal wavelength may be defined as [11]:

$\eta=\frac{\sigma_{\varepsilon}}{\sigma_{a}}$

From Eqs.(14) and (15) with the aid of (17) and the definition of $g *$ given by Eq.(16), we get:

$g_{\circ}=g^{*} \frac{W_{P} \tau_{21}+\left(W_{S a}-\eta^{-1} W_{S e}\right) \tau_{21}-\eta^{-1}}{W_{P} \tau_{21}+\left(W_{S a}+W_{S e}\right) \tau_{21}+1}$

and from Eqs.(3) to (6) with (17), we get

$$
\begin{aligned}
& W_{p}=\frac{\sigma_{P a} p_{P}}{h v_{p} A} \\
& W_{S e}=\frac{\sigma_{\varepsilon} p_{s}}{h v_{s} A} \\
& W_{S a}=\frac{\sigma_{a} p_{s}}{h v_{S} A}=\frac{\sigma_{\varepsilon} P_{s}}{\eta h v_{s} A}
\end{aligned}
$$

The gain coefficient of a homogeneously broadened be written as [12]

$$
g(w)=\frac{g_{。}}{1+\left(w-w_{a}\right)^{2} T_{2}^{2}+P / P_{\text {sat }}}
$$

where $\mathrm{g} 0$ is the peak value, $\omega$ is the frequency of the incident signal, $\omega \mathrm{a}$ is the atomic transition frequency and $\mathrm{P}$ is the optical power of the continuous wave CW signal being amplified. The saturation power Psat depends on doping parameters such as the fluorescence time $\mathrm{T} 1$ and the transition cross section $\sigma$. The parameter T2 in Eq.(18) is known as the dipole relaxation time and is typically quite small $(0.1 \mathrm{ps})$ for fiber amplifiers. Considers the amplification factor defined as $\mathrm{G}=$ Pout/Pin, where Pin and Pout are the input and output powers of the $\mathrm{CW}$ signal being amplified. The amplification factor is obtained by solving [13]

$$
\frac{d P}{d z}=g(w) P(z)
$$

where $\mathrm{P}(\mathrm{z})$ is the optical power at a distance $\mathrm{z}$ from the input end of the amplifier. A straight forward integration with the conditions $\mathrm{P}(0)=$ Pin and $\mathrm{P}(\mathrm{L})=$ Pout shows that the amplification factor for an amplifier of length $\mathrm{L}$ is given by [14]

$$
G_{o}=G(w)=\exp \left(\int_{0}^{L} g(w) d z\right)=\exp [g(w) L]
$$

where $\mathrm{G}$ is the unsaturated amplifier gain is assumed to be constant along the amplifier length. Both $G(\omega)$ and $\mathrm{g}(\omega)$ are maximum at $\omega=\omega$ a and decrease when $\omega \neq$ $\omega$ a. However, $G(\omega)$ decreases much faster than $g(\omega)$ because of the exponential dependence. Substituting $g$ from Eq.(23) in Eq.(22), to obtain

$$
\frac{d P}{d z}=\frac{g_{\mathrm{o}} P}{1+P / P_{\text {sat }}}
$$

where $\mathrm{g}^{\mathbf{0}}$ is the small-signal gain coefficient at a given wavelength, $\mathrm{P}$ is the signal power, and Psat is the saturated signal power, defined as the power required for the gain to drop $3 \mathrm{~dB}$ [4]. This equation can be easily integrated over the amplifier length. By using the initial condition $\mathrm{P}(0)=$ Pin together with $\mathrm{P}(\mathrm{L})=$ Pout $=$ GPin , and by using Eqs.(18) and (22), the amplifier gain is given by the implicit relations after some manipulation $[9,14]$

$$
\begin{aligned}
& \ln \left(\frac{P_{\text {out }}}{P_{\text {in }}}\right)+\frac{1}{P_{\text {sat }}}\left(P_{\text {out }}-P_{\text {in }}\right)=g_{0} L \\
& G=G_{\circ} \exp \left\{-(G-1) \frac{P_{\text {in }}}{P_{\text {sat }}}\right\} \\
& G_{\circ}=\exp \left(g_{s} L\right)
\end{aligned}
$$

With the saturation signal power of [18]

$$
P_{s a t}=\frac{h v_{s} A}{\left(\sigma_{a}+\sigma_{\varepsilon}\right) \tau_{21}}=\frac{\eta h v_{s} A}{(1+\eta) \sigma_{\varepsilon} \tau_{21}}
$$




\section{Results and discussion}

The following data (table) are used in simulation program for ytterbium doped lead flouroborate glass fiber amplifiers at $968 \mathrm{~nm}$ pumping wavelength.

Table: Typical YDFA parameters, with $\left({ }^{2} F_{5 / 2} \rightarrow{ }^{2} F_{7 / 2}\right.$ ) transition $\mathrm{Yb}+3$ doped lead flouroborate glass [13].

\begin{tabular}{|c|c|c|}
\hline Symbol & Definitions & Value \\
\hline$\sigma a$ & Pump absorption cross sections & $\begin{array}{c}2.56 \times 10-24 \\
\mathrm{~m} 2\end{array}$ \\
\hline$\sigma \mathrm{e}$ & Signal emission cross sections & $\begin{array}{c}1.07 \times 10-24 \\
\mathrm{~m} 2\end{array}$ \\
\hline$\lambda \mathrm{s}$ & Signal Wavelength & $1022 \mathrm{~nm}$ \\
\hline$\lambda \mathrm{p}$ & Pump wavelength & $968 \mathrm{~nm}$ \\
\hline$\tau 21$ & E2-E1 transition lifetime & $0.81 \mathrm{~ms}$ \\
\hline $\mathrm{a}$ & Core radius of the fiber & $(2-10) \mu \mathrm{m}$ \\
\hline $\mathrm{L}$ & Length of the fiber & $(2-15) \mathrm{m}$ \\
\hline $\mathrm{pp}$ & Pump power & $(0-40) \mathrm{mW}$ \\
\hline ps & Signal power & $1 \mu \mathrm{W}$ \\
\hline$\eta$ & $\begin{array}{l}\text { The ratio emission-to- } \\
\text { absorption cross sections }\end{array}$ & 0.65 \\
\hline
\end{tabular}

The characteristics of the $\mathrm{Yb}+3$ doped fiber amplifiers pumping at $968 \mathrm{~nm}$ wavelengths can analyzed by employing an amplifier based on population of a classical model. The gain carve is exponentially increased with ion concentration and saturate after a certain level. The amplifier reaches population inversion, high concentration or long fibers are required to absorb efficiently the pump power. In long fibers, the absorption of the signal wavelength will reduce the efficiency of the amplifier, since the amplifier gain must first compensate the propagation losses. For this reason, we have chosen to increase the doping level to keep the fiber short and increasing a transition cross section. Figures 2, 3 and 4 represent the gain versus ion concentration; figure 2 shows that pumping powers 25 and $50 \mathrm{~mW}$ has no deference which give approximately $60 \mathrm{~dB}$ gain, so $25 \mathrm{~mW}$ is the optimum value, figure 3 explains that any increase in fiber length means increase in gain but at the same time increasing length causes decreasing in ion concentration, in agreement with[14,15]. Figure 4 shows $5 \mu \mathrm{m}$ core radius gives efficient gain $60 \mathrm{~dB}$. Figures 5,6 and 7 demonstrate the gain with pump power; the threshold value of pump power can be determined, figure 5 shows that larger ion concentration means high gain but the threshold value of pumping power clamped at $2 \mathrm{~mW}$, in figure $6,15 \mathrm{~m}$ length reach $62 \mathrm{~dB}$ with pumping power less than $4 \mathrm{~mW}$, in figure 7 when core radius is increased causes differ in threshold value of pump power, acceptance reference [16] in other side we can see that the gain value is from 60 to $62 \mathrm{~dB}$, therefore $2.5-5 \mu \mathrm{m}$ core radius are the optimum value. Figures 8,9 and 10 gain as a function of fiber length; as it clear from figure 8 increasing ion concentration meting by decreasing in fiber length, for $3.5 \times 1025 \mathrm{ion} / \mathrm{m} 3$ and $4.5 \times 1025 \mathrm{ion} / \mathrm{m} 3$ the gain is within the optimum value, over than $60 \mathrm{~dB}$, figure 9 make us sure that $25 \mathrm{~mW}$ is the best value for such amplifier, as in [16], figure 10 shows that the highest gain $62 \mathrm{~dB}$ for $5 \mu \mathrm{m}$ core radius with long fiber while $2.5 \mu \mathrm{m}$ core radius gives $60 \mathrm{~dB}$ for short fiber. Figures 11,12 , and 13 amplifier gain as a function of core radius; figure 11 shows that for ion concentration $4.5 \times 1025 \mathrm{ion} / \mathrm{m} 3$, the core radius must be larger than $0.4 \mu \mathrm{m}$, the gain curve is appear with gain value larger than $60 \mathrm{~dB}$, for all ion concentration the gain curves after $10 \mu \mathrm{m}$ are dropped sharply to zero value because of pump power $25 \mathrm{~mW}$ cannot excite ions at $10 \mathrm{~m}$ length and $11 \mu \mathrm{m}$ core radius, while in figure $12,50 \mathrm{~mW}$ pump power can excite ions at fiber length of $10 \mathrm{~m}$ and core radius larger than $10 \mu \mathrm{m}$ and gain value is stayed within the optimum value lager than $60 \mathrm{~dB}$, figure 13 shows that $4-7 \mu \mathrm{m}$ core radius is optimum value for $10 \mathrm{~m}$ length, $25 \mathrm{~mW}$ and $3.5 \times 1025 \mathrm{ion} / \mathrm{m} 3$.

\section{Conclusion}

According to the results, it was clear that the pump power applied to YDFA sharply reduces due to efficient absorption ytterbium ion. Amplifier gain is strongly dependent on the fiber length, pumping power, ion concentration and core radius. It is possible to design amplifiers of large gain with few meter length and high ion concentration and vice versa. Any increase in the fiber core radius would increase the threshold pump power. 


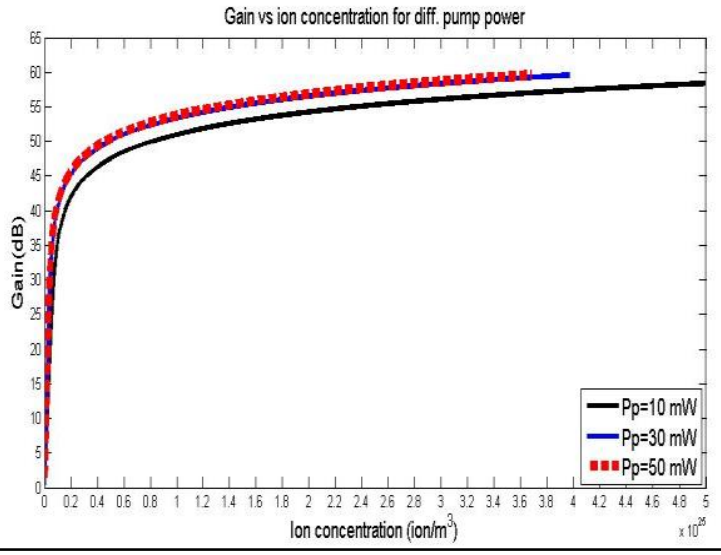

Figure(2): Gain vs. ion concentration at diff. pump power of (YDFA), $L=10 \mathrm{~m}, \lambda \mathrm{p}=968 \mathrm{~nm}, \lambda \mathrm{s}=1022 \mathrm{~nm}, \mathrm{a}=2.5 \mu \mathrm{m}$.

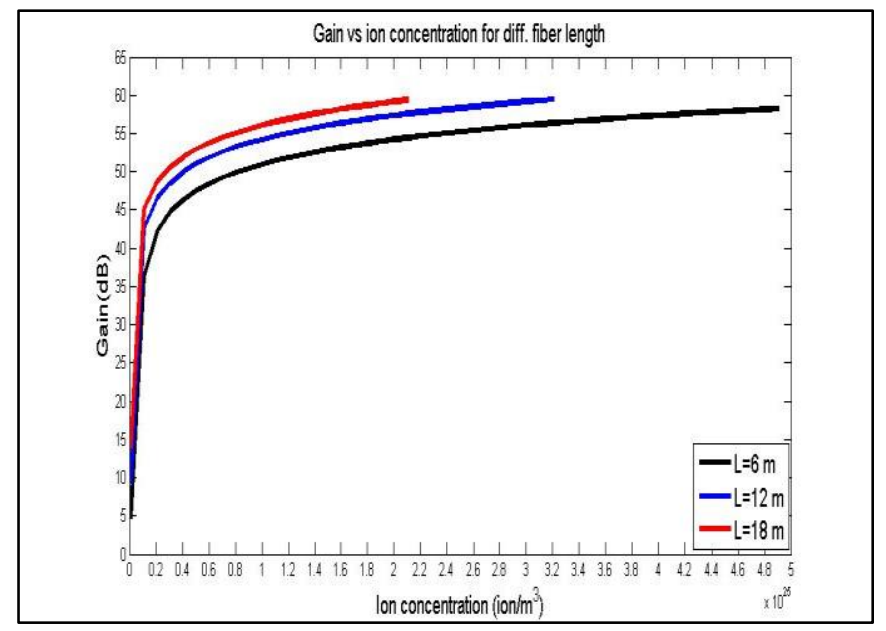

Figure (3): Gain vs. ion concentration at diff. fiber length of (YDFA), $p p=25 \mathrm{~mW}, \lambda \mathrm{p}=968 \mathrm{~nm}, \lambda \mathrm{s}=1022 \mathrm{~nm}$, $\mathrm{a}=2.5 \mathrm{um}$.

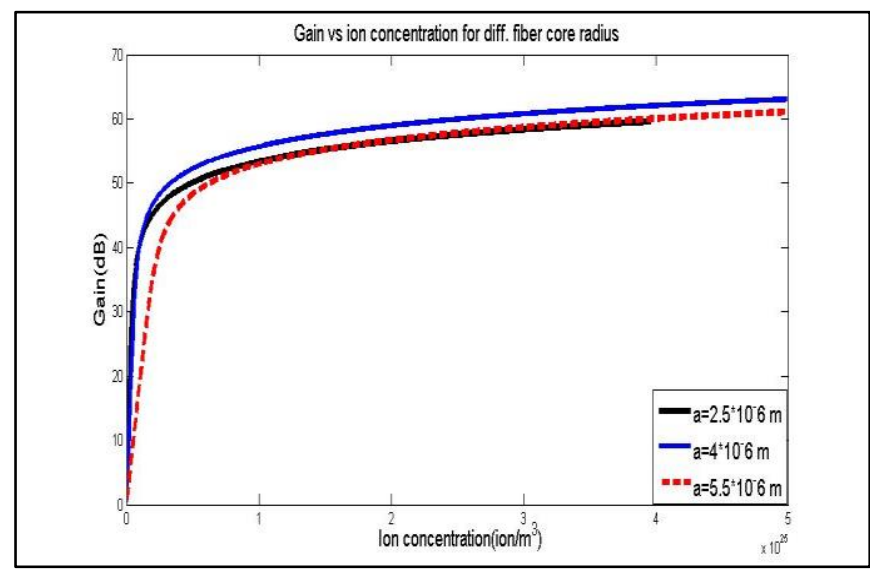

Figure (4): Gain vs. ion concentration at diff. core radius of (YDFA), $\mathrm{L}=10 \mathrm{~m}, \lambda \mathrm{p}=968 \mathrm{~nm}, \lambda \mathrm{s}=1022 \mathrm{~nm}, \mathrm{pp}=25$ $\mathrm{mW}$.

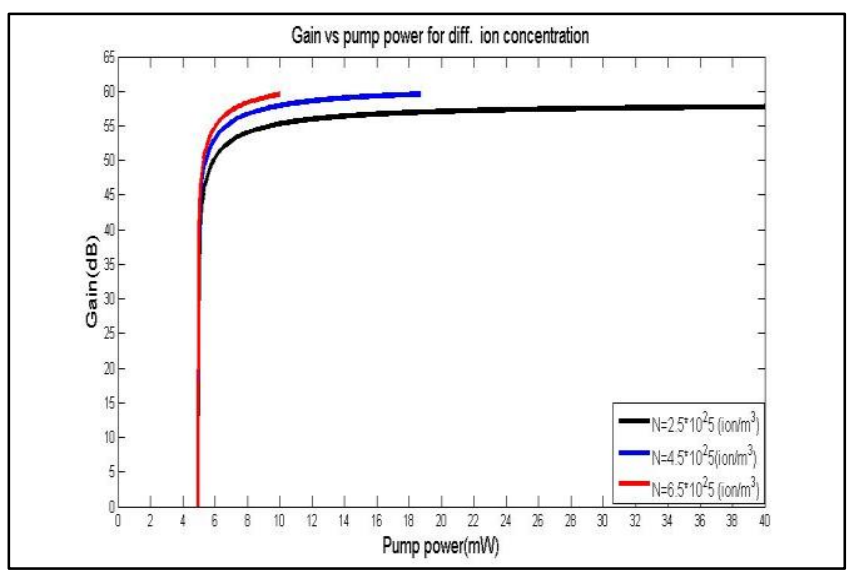

Figure (5): Gain vs. pump power at diff. ion concentration of (YDFA), $\mathrm{L}=10 \mathrm{~m}, \lambda \mathrm{p}=968 \mathrm{~nm}$, $\lambda \mathrm{s}=1022 \mathrm{~nm}, \mathrm{a}=2.5 \mu \mathrm{m}$.

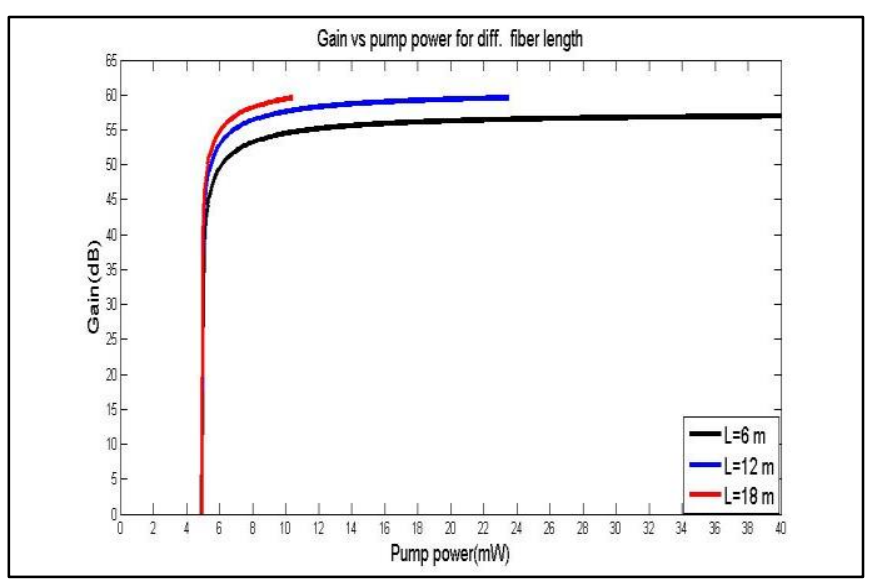

Figure (6): Gain vs. pump power at diff. fiber length of (YDFA), $\lambda \mathrm{p}=968 \mathrm{~nm}, \lambda \mathrm{s}=1022 \mathrm{~nm}, \mathrm{a}=2.5 \mu \mathrm{m}$, $\mathrm{N}=3.5 \times 1025$ ion $/ \mathrm{m} 3$.

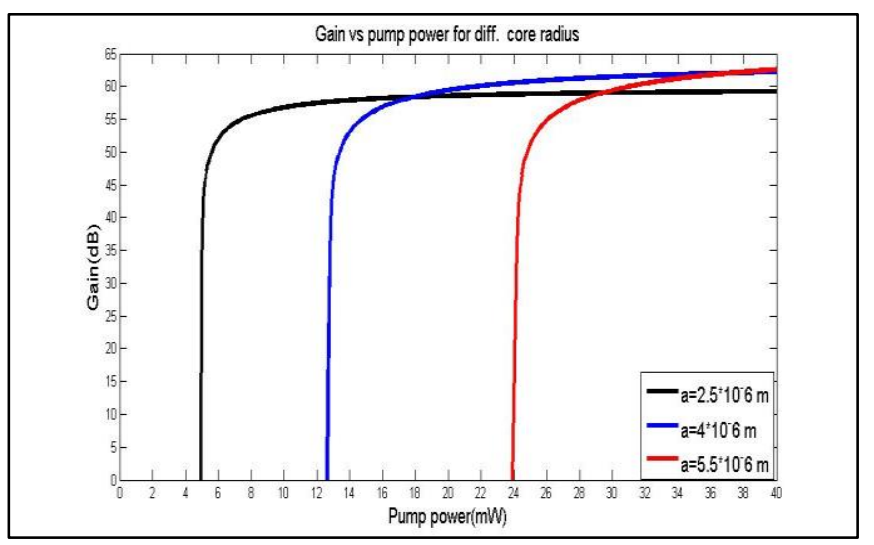

Figure (7): Gain vs. pump power at diff. core radius of (YDFA), L=10m, $\lambda \mathrm{p}=968 \mathrm{~nm}, \lambda \mathrm{s}=1022 \mathrm{~nm}, \mathrm{~N}=3.5 \times 1025$ ion $/ \mathrm{m} 3$. 


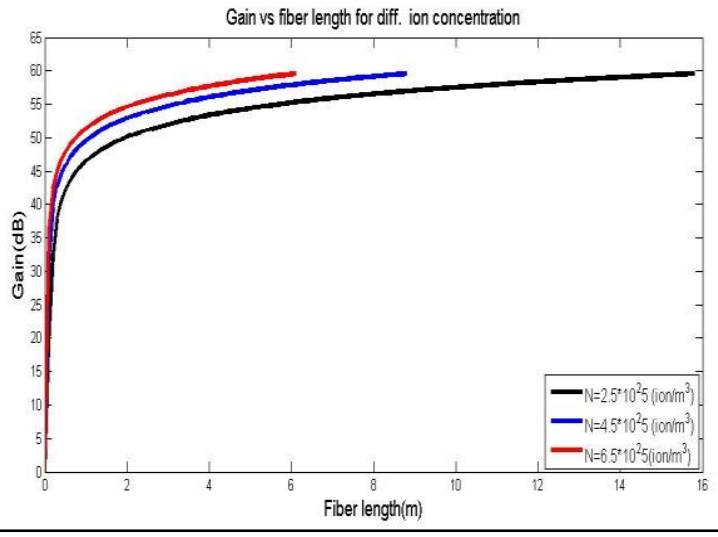

Figure (8): Gain vs fiber length at diff. ion concentration of (YDFA), $p p=25 \mathrm{~mW}, \lambda \mathrm{p}=968 \mathrm{~nm}, \lambda \mathrm{s}=1022 \mathrm{~nm}$, $\mathrm{a}=2.5 \mathrm{um}$.

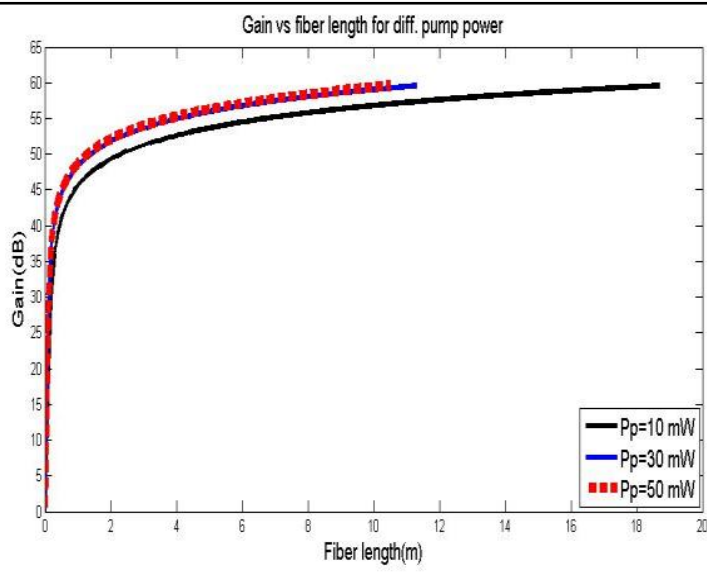

Figure (9): Gain vs. fiber length at diff. pump power of (YDFA), $\lambda \mathrm{p}=968 \mathrm{~nm}, \lambda \mathrm{s}=1022 \mathrm{~nm}, \mathrm{a}=2.5 \mu \mathrm{m}$, $\mathrm{N}=3.5 \times 1025$ ion $/ \mathrm{m} 3$.

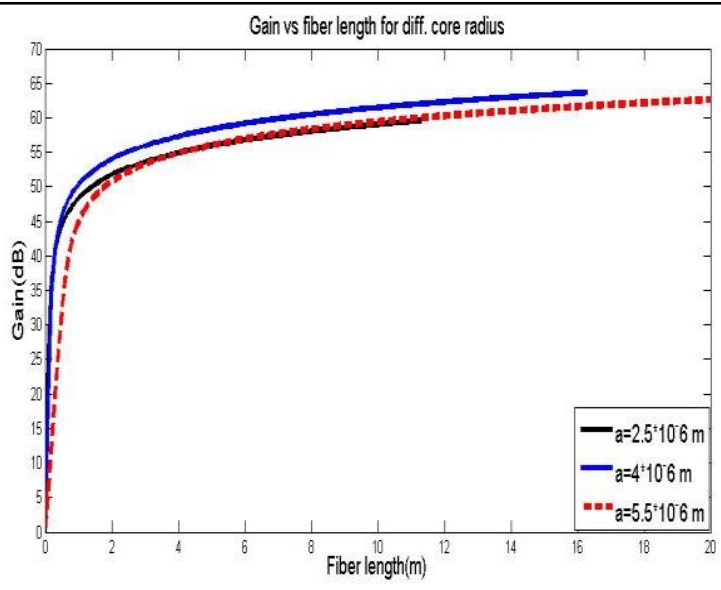

Figure (10): Gain vs. fiber length at diff. core radius of (YDFA), $p p=25 \mathrm{~mW}, \lambda \mathrm{p}=968 \mathrm{~nm}, \lambda \mathrm{s}=1022 \mathrm{~nm}$, $\mathrm{N}=3.5 \times 1025 \mathrm{ion} / \mathrm{m} 3$.

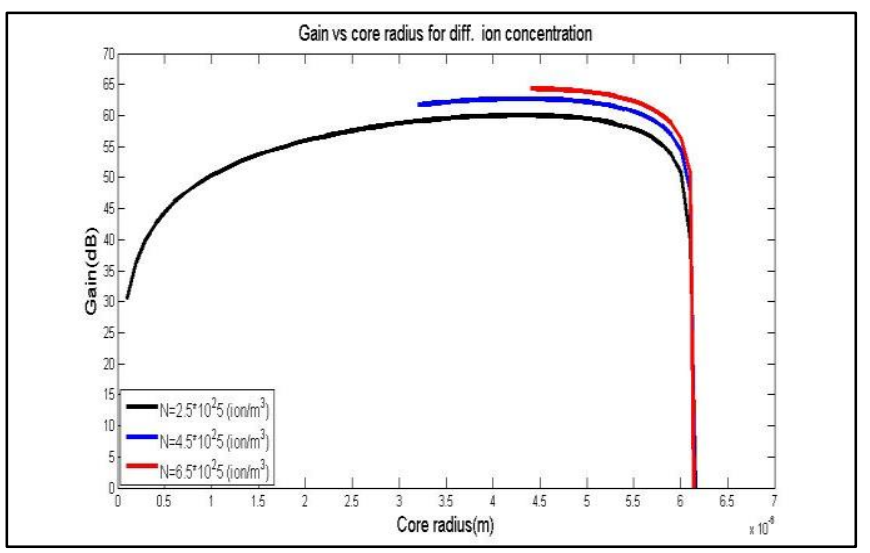

Figure (11): Gain vs core radius at diff. ion concentration of (YDFA), $L=10 \mathrm{~m}, \lambda \mathrm{p}=968 \mathrm{~nm}, \lambda \mathrm{s}=1022 \mathrm{~nm}, \mathrm{pp}=25$ $\mathrm{mW}$.

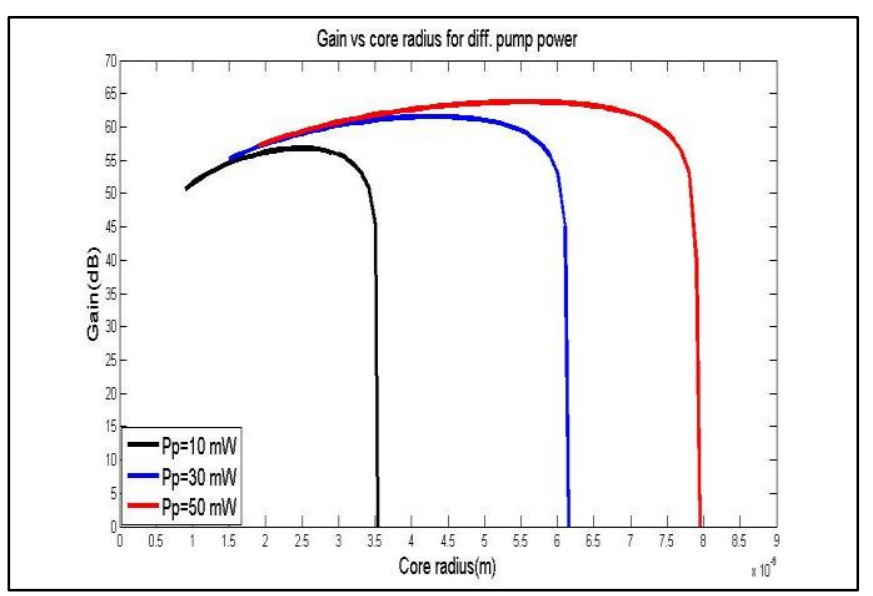

Figure (12): Gain vs. core radius at diff. pump power of (YDFA), $\mathrm{L}=10 \mathrm{~m}, \lambda \mathrm{p}=968 \mathrm{~nm}, \lambda \mathrm{s}=1022 \mathrm{~nm}, \mathrm{~N}=3.5 \times 1025$ ion $/ \mathrm{m} 3$.

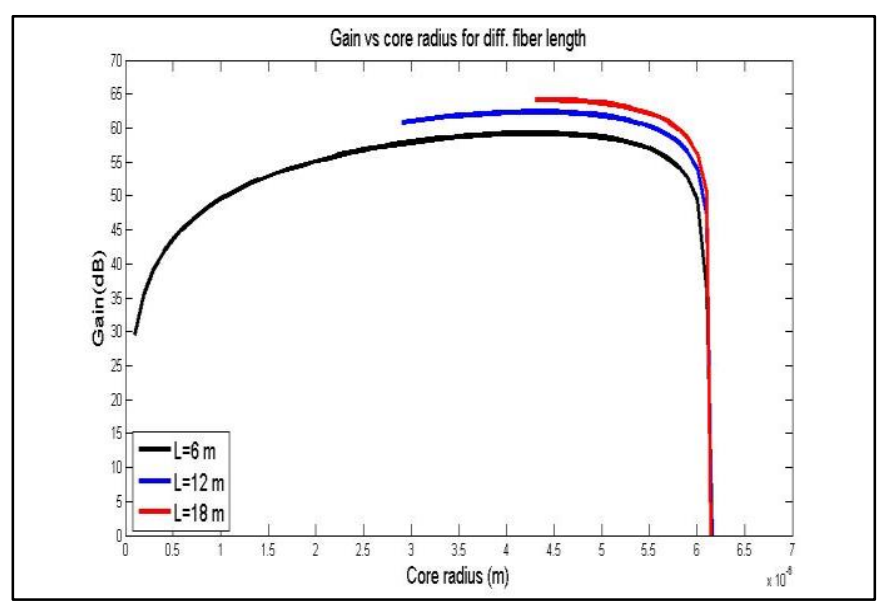

Figure (13): Gain vs. core radius at diff. fiber length of (YDFA), $p p=25 \mathrm{~mW}, \lambda \mathrm{p}=968 \mathrm{~nm}, \lambda \mathrm{s}=1022 \mathrm{~nm}$, $\mathrm{N}=3.5 \times 1025$ ion $/ \mathrm{m} 3$. 


\section{References}

1- John M. Senior," Optical Fiber Communications Principles and Practice" Third edition, Pearson Education Limited ISBN: 978-0-13-032681-2. 2009.

2- Surinder Singh," Simulation and Optimization of Optical Amplifiers in Optical Communication Networks" Ph.D. thesis, Thapar University, Patiala (Punjab) India, 2007.

3- A. W. Naji, B. A. Hamida, X. S. Cheng, M. A. Mahdi, S. Harun, S. Khan, W. F. AL-Khateeb, A. A. Zaidan, B. B. Zaidan and H. Ahmad. ," Review of Erbium-doped fiber amplifier" International Journal of the Physical Sciences Vol. 6(20), 2011.

4- Abdel Hakeim M. Husein \& Fady I. EL-Nahalb," Model of Temperature Dependence Shape of Ytterbium -doped Fiber Amplifier Operating at 915 nm Pumping Configuration" (IJACSA), Vol. 2, No. 10, 2011.

5- Peiying Chen, Suqin Feng, Lanzhu An , Haixu Song , Ximei Zhao, and Cunge Xu," Crystal Fiber Based Erbium Doped Amplifiers and Their Gain" International Journal of Future Computer and Communication, Vol. 1, No. 1, June 2012.

6- Bill Petar Petreski, " Characterization of optical fiber amplifiers" Ph.D. thesis ,Victoria University of Technology ,1997.

7- Govind P. Agrawal," Applications of Nonlinear Fiber Optics" Academic Press, 2001.

8- Sorin Miclos, Dan Savastru, and Ion Lancranjan, " Theoretical analysis of a high power fiber laser", Recent Researches in Applied Mathematics, ISBN: 978-1-61804-016-9, 2011.

9- Dan Savastru, Sorin Miclos, and Ion Lancranjan, " Theoretical Analysis of A passively Q-switched Erbium Doped Fiber Amplifiers" Romanian Association of Nonconventional Technology, 2012.

10- Efraín Mejía-Beltrán," Rare-Earth Doped Optical Fibers" Selected Topics on Optical Fiber Technology,2012.

11- Osama Mahran," Gain and Noise Figure of Ytterbium Doped Lead Fluoroborate Optical
Fiber",Australian Journal of Basic and Applied Sciences, ISSN 1991-8178, 2010.

12- A.Cem Çokrak \& Ahmet ALTUNCU," Gain and noise figure performance of Erbium Doped Fiber Amplifiers (EDFA)"Journal of Electrical and Electronics Engineering, no.2, vol.4,2004.

13- O. Mahran, M. Salem, M.S. Helmi, and G.D. Roston," Factors Effect on the Saturation Parameter $\mathrm{S}$ and there Influences on the Gain Behavior of Ytterbium Doped Fiber Amplifier"Aust. J. Basic \& Appl. Sci., 5(12), 2011.

14- M.A.Othman, M.M. Ismail, M. H. Misran, M. A.M.Said, and H.A. Sulaiman, " Erbium Doped Fiber Amplifier EDFA for C-Band Optical Communication System", International Journal of Engineering \& Technology IJET-IJENS Vol.12 No.4, 2012.

15- Mikko Söderlund," Characterization and Analysis of Photo darkening in Double Cladding Ytterbium -Doped Silica Fibers" Doctoral Dissertation, Helsinki University of Technology, 2009 Mikko Söderlund.

16-Catalin Florea et al," Ytterbium-Doped Glass Waveguide Laser Fabricated by Ion Exchange"Journal of Lightwave Technology, vol. 17, no. 9, 1999. 